\title{
Risk for mother to child HIV-1 infection was increased by breast feeding
}

Nduati R, John G, Mbori-Ngacha D, et al. Effect of breastfeeding and formula feeding on transmission of HIV-1.A

randomized clinical trial.JAMA 2000 Mar 1;283:1167-74.

\section{QUESTION: In the infants of HIV-1 infected women, does formula feeding instead of breast feeding reduce the rate of HIV-1 transmission and mortality?}

\section{Design}

Randomised (allocation concealed*), blinded (investigators to interim results),* controlled trial with 2 year follow up.

\section{Setting}

4 antenatal clinics in Nairobi.

\section{Patients}

425 HIV-1 infected pregnant women (mean age 23 y) who resided in Nairobi and had access to municipally treated water. 401 mother-infant pairs (94\%) were included in the analysis.

\section{Intervention}

Women were allocated to breast feed $(n=212)$ or formula feed $(n=213)$ their infants. Women in the formula feed group were told to feed their infant with a cup and had to demonstrate proper formula preparation and cup feeding to a visiting nurse.

\section{Main outcome measures}

Infant HIV-1 infection and mortality within the first 2 years. Mortality rates were compared using KaplanMeier survival analysis.

\section{Main results}

Analysis was by intention to treat. At 24 months, the cumulative probability of HIV-1 infection was higher in breastfed infants than in formula fed infants $(p=0.001)$ (table). A significant difference existed between breastfed and formula fed infants at all ages after birth, with a $10.2 \%$ cumulative difference occurring at 6 weeks (CI 3.1 to $17.3, p=0.005)$. The groups did not differ for mortality $(p=0.30)$ (table), and no difference existed at any age after birth.

\section{Conclusions}

In HIV-1 infected women, breast feeding was associated with a greater transmission rate of HIV-1 infection to infants than was formula feeding, with a $10 \%$ difference between groups occurring by 6 weeks of age. The method of feeding did not affect mortality rates at 2 years.
*See glossary.

Source of funding: National Institutes of Health.

For correspondence: Dr J Kreiss, Box 359931, Harborview Medical Center, 325 Ninth Avenue, Seattle, WA 98104-2499 USA. Fax +1206731 2427.

Breast feeding $v$ formula feeding for infants of HIV-1 infected mothers at 24 monthst

\begin{tabular}{lllll} 
& \multicolumn{2}{l}{ Cumulative rates } & & \\
\cline { 2 - 3 } Outcomes & $\begin{array}{l}\text { Breast } \\
\text { feeding }\end{array}$ & $\begin{array}{c}\text { Formula } \\
\text { feeding }\end{array}$ & ARI (95\% CI) & NNH (CI) \\
\hline HIV-1 infection & $37 \%$ & $21 \%$ & $16 \%(6.5$ to 26$)$ & $7(4$ to 16$)$ \\
\hline Mortality & $24 \%$ & $20 \%$ & $4 \%(-4$ to 13$)$ & Not significant \\
\hline
\end{tabular}

†Abbreviations defined in glossary; $\mathrm{NNH}$ and $\mathrm{Cl}$ calculated from data in article.

\section{COMMENTARY}

The study by Nduati et al, done in a resource poor setting where breast feeding is the norm, confirmed that breastfed infants are at increased risk for HIV-1 infection. Applying these results in practice, however, is not easy. A major issue, raised by the authors themselves, is the lack of acceptability of formula feeding. In the study, many women in the formula feeding group admitted to breast feeding. The stigma associated with not breast feeding, the convenience of breast feeding, the cost of formula, and the potential for increased early mortality in infants not breast fed all add to the difficulties of implementing a change in feeding patterns in these settings. Perhaps we should instead be looking at strategies to reduce the risk for HIV-1 transmission despite breast feeding. ${ }^{1}$

One strategy might be to use antiretroviral agents postpartum to prevent mother to child transmission. In a Ugandan trial, nevirapine was given as a single dose intrapartum and to the infant at 2 to 3 days. ${ }^{2}$ Nearly all the infants were breast fed, and the transmission rates at 2 and 4 months were $11.9 \%$ and $13.1 \%$, respectively.

A second strategy might be to determine whether a period of breast feeding exists that optimises the benefits and minimises the risk for transmission of HIV-1. Unfortunately, it appears that the early weeks of breast feeding, which provide the greatest benefit, are also when the highest risk for transmission exists.

A third strategy might be to consider other factors that could affect transmission from breast milk. For example, in an observational study of 549 infants in South Africa, the rates of HIV-1 transmission at 3 months in those who were either formula fed, mixed fed, or exclusively breast fed were $18.8 \%, 24.1 \%$, and $14.6 \%$, respectively. ${ }^{4}$ The intriguing possibility that the exclusion of other food modifies HIV-1 transmission from breast milk needs further study.

Susan King, MD

Hospital for Sick Children Toronto, Ontario, Canada

1 De Cock KM, Fowler MG, Mercier E, et al. Prevention of mother-to-child HIV transmission in resource-poor countries: translating research into policy and practice. JAMA 2000;283:1175-82.

2 Guay LA, Musoke P, Fleming T, et al. Intrapartum and neonatal single-dose nevirapine compared with zidovudine for prevention of monther-to-child transmission of HIV-1 in Kampala, Uganda: HIVNET 012 randomised trial. Lancet 1999;354:795-802.

3 Miotti PG, Taha TE, Kumwenda NI, et al. HIV transmission through breastfeeding: a study in Malawi. JAMA 1999;282:744-9.

4 Coutsoudis A, Pillay K, Spooner E, et al. Influence of infant-feeding patterns on early mother-to-child transmission of HIV-1 in Durban, South Africa: a prospective cohort study. South African Vitamin A Study Group. Lancet 1999;354:471-6. 